\title{
Entry, Reputation, and Intellectual Property Rights Enforcement
}

\author{
Jiahua Che, Larry Qiu, and Wen Zhou*
}

April 24, 2013

\begin{abstract}
We examine how reputation concerns induce a multinational to partly withhold its entry into a developing country under weak intellectual property rights (IPR) enforcement. Equilibrium IPR violations are shown to arise only in the presence of such concerns. Holding constant a multinational's incentive to innovate, better IPR enforcement encourages entry, but reduces social welfare. The multinational's incentive to innovate may be inversely U-shaped in the strength of IPR enforcement. If timed properly, however, stronger IPR enforcement can foster innovation without compromising social welfare. Testable implications concerning observable IPR violations are derived.
\end{abstract}

Keywords: entry, reputation, intellectual property rights.

JEL Code: D82, F10, F12, F23

\section{Introduction}

We analyze how the strengthening of intellectual property rights (IPR) enforcement in developing countries affects multinationals' entry into these countries. Existing studies typically assume weak IPR to be the only imperfection obstructing such entry. In reality, however, developing countries suffer from many other imperfections. We show that taking these imperfections into account generates new insights into our understanding of IPR enforcement in developing countries.

The particular imperfection that we consider here is information asymmetry between consumers and multinationals with regard to the latter's product quality. Although consumers in developing countries expect multinationals to offer better quality products on average, evidence shows that they are not always aware of top-notch brand names, let alone the quality of all foreign products. A recent study of the Chinese luxury market by McKinsey and Company (2011), for example, reports that in 2008 only 23 percent of the country's wealthy consumers could name more than three ready-to-wear international brands and that only 44 percent were aware that the prices of luxury products sold in China were at least 20 percent higher than those in overseas markets. ${ }^{1}$

*Jiahua Che: Department of Economics, Chinese University of Hong Kong; Larry Qiu (corresponding author, larryqiu@hku.hk): School of Economics and Finance, University of Hong Kong; Wen Zhou: School of Business, University of Hong Kong. We are grateful for the helpful comments of Chong-en Bai, Hongbin Cai, Jacques Cremer, Tanjim Houssain, David Levine, Zhigang Tao, Cheng Wang, Yong Wang, Li-An Zhou and the seminar participants at Katholieke Universiteit Leuven, City University of Hong Kong, and the Third Asia-Pacific Trade Seminars (Shanghai). The comments and suggestions made by the editor and two anonymous referees have also greatly helped to improve the paper.

${ }^{1}$ Taking advantage of this ignorance, some foreign companies export products made in China and then re-import and sell them as foreign brands that do not actually exist. In addition, multinationals sometimes fail or are un- 
In the face of such asymmetric information, a multinational's entry choice will affect its reputation. We first analyze a multinational's entry under the assumption of symmetric information as a benchmark. Without any reputation concerns, a multinational will fully enter a developing country, outpricing copycats no matter how weak IPR enforcement is. Although no imitation takes place in equilibrium, potential competition from imitators trims the multinational's profits and hence diminishes its ex ante incentive to innovate. Thus, we obtain the typical insight that strengthening IPR enforcement encourages innovation and technology transfer.

Under information asymmetry, we show that a high-quality multinational can signal its quality by limiting the scale of its entry, whereas its low-quality counterpart always engages in full-scale entry. This signaling mechanism resonates with the celebrated work of Spence (1973), who showed that more capable individuals would find it less costly to signal their ability through education than their less capable peers. A similar logic underlies our result. Weak IPR enforcement forces a multinational to incur a cost to mask its technology upon entry, and that cost is higher for a high-quality multinational. Because the foregone profit will be lower, a high-quality multinational finds it less costly to signal by withholding entry than a low-quality multinational. Such withholding of entry in turn leaves room for imitation, which takes place in equilibrium if and only if IPR enforcement is sufficiently weak. This last observation highlights an important feature that is largely ignored in the existing literature: IPR violation is observable under weak enforcement only in the presence of other forms of imperfection. A number of testable implications emerge from this observation. In particular, we show that the scale of observed IPR violations increases with the growth rate of the host country's economy and the quality premium of the products and decreases with the interest rate.

Our model also allows us to examine the effects of strengthening IPR enforcement. First, a multinational will enter more aggressively when IPR enforcement is strengthened, which roughly matches empirical observations (see, for example, Maskus and Penubarti, 1995; Smith, 2001; Branstetter et al., 2006; Ivus, 2010; Branstetter et al., 2011).

Second, holding constant the incentive to innovate, strengthened IPR enforcement can reduce social welfare. We obtain this result by assuming perfectly inelastic demand, such that the inefficiency does not stem from the multinational's monopoly power. Rather, imitation in unserved markets represents a social gain, and stronger IPR enforcement reduces that gain without sufficiently expanding the multinational's entry. Under symmetric information, in contrast, better IPR enforcement merely redistributes the social surplus between consumers and the multinational without changing its total amount.

Third, a multinational may not always benefit from better IPR enforcement. Imitation presents a high-quality multinational with the following tradeoffs. In the places the multinational enters, competition from potential imitators trims its profits. In the places that the multinational chooses not to enter,

able to maintain product quality in developing countries as rigorously as they do in their home countries. McDonald's, Carrefour, and Wal-Mart have all been exposed as selling substandard products in China in recent years (http://www.usatoday.com/money/industries/food/story/2012-03-16/china-mcdonalds-carrefour-chicken-fines/53565980/1). 
however, imitation brings an efficiency gain that may be shared by the multinational through litigation. The multinational's payoff may then be inversely U-shaped in IPR strength, which leads to a similar relationship between the innovation incentive and IPR strength. This relationship echoes the empirical findings of Scherer (1967) and Aghion et al. (2005).

Fourth, the timing of IPR improvement is important. In an environment characterized by information asymmetry, the deferred improvement of IPR enforcement can foster multinationals' innovation without compromising social welfare.

Earlier research on IPR protection in developing countries probed the relationship between imitation in these countries and innovation in developed countries without explicitly considering multinationals' entry choices. Segerstrom et al. (1990) and Helpman (1993) assumed imitation to be the only means of technology transfer, and suggested that imitation in developing countries allows their labor force to make use of existing innovations, thus leaving the labor force in developed countries free to specialize in future innovations. ${ }^{2}$ This insight promoted a number of researchers to consider other channels of technology transfer. Lai (1998), and subsequently Branstetter and Saggi (2011), Dinopoulos and Segerstrom (2010), and Gustafsson and Segerstrom (2011), argued that if technologies can be transferred through direct investment, then weak IPR protection allows imitators to compete labor away from foreign investment, thus forcing multinationals to keep production in developed countries, which in turn competes labor away from innovation.

This line of research shares two assumptions. First, labor in a developing country can engage only in imitation unless employed by multinationals. Accordingly, increased imitation always takes labor away from foreign investments rather than from other indigenous economic activities. Second, there is no possibility of contracting (such as licensing) between multinationals and domestic firms. Yang and Maskus (2001) and Yang and Maskus (2009) departed from these two assumptions. Both papers adopt a partial equilibrium framework in which, as the only channel of technology transfer, a multinational can license a copycat, and the production cost is unaffected by IPR strength. Reaching the same conclusion that weak IPR protection hurts multinationals by expanding licensees' options to imitate, Yang and Maskus (2001) nevertheless observed that imitation will not take place in equilibrium when licensing is an option. This observation was confirmed by Yang and Maskus (2009), who showed that imitation will take place only in the limiting situation that IPR protection is entirely absent. Finally, Ethier and Markusen (1996) considered both licensing and direct investment in addition to exporting to a developing country in which IPR protection is completely absent. They did not examine how IPR protection affects entry mode or innovation, but nevertheless also found imitation not to occur in equilibrium.

Our contributions can be summarized as follows. We adopt a partial equilibrium framework that

\footnotetext{
${ }^{2}$ Grossman and Helpman (1991) offered another explanation for why imitation in developing countries may facilitate innovation in developed countries. If continual innovation in developed countries is motivated only by the competition threat from imitation in developing countries, then any measure that reduces imitation in those countries will also reduce innovation in the former (see also Glass and Saggi, 2002; Glass and Wu, 2007). A similar argument lies behind the results reported by Aghion et al. (2001) and Aghion et al. (2005) in a more general setting. Bessen and Maskin (2009) suggested that existing innovation may complement future innovation, and as a result, weak IPR protection facilitates future innovation by allowing a cheaper access to existing innovation.
} 
considers both direct investment and licensing as entry options. The licensing option allows multinationals to contract with potential imitators. In addition to weak IPR enforcement, information asymmetry is introduced as an additional imperfection. We develop three key insights. First, when weak IPR enforcement is the only imperfection, imitators can be priced out of competition whenever licensing is feasible. Imitation takes place in equilibrium only in the presence of additional imperfections such as information asymmetry. Second, equilibrium imitation becomes a channel of technology transfer that brings efficiency gains, which can be shared by multinationals through moderately strong IPR enforcement. Third, although it transfers technology and benefits multinationals, imitation is less efficient than legitimate channels of technology transfer. It emerges as a supplement only when some other imperfections prevent multinationals from taking full advantage of legitimate transfers.

We would like to emphasize, however, that we are not arguing the case for whether multinationals benefit from weak IPR enforcement in real life, which is an empirical issue. Nor do we wish to advocate any particular nation disregarding IPR protection. Nevertheless, as a theoretical possibility, our insight that imitation can result in efficiency gains and that multinationals can share in that gain through moderately strong IPR enforcement remains an intriguing one. It also does not seem too far-fetched, as our prediction of inverted U-shaped relationships between IPR strength and multinational profits is consistent with empirical studies.

The remainder of the paper is organized as follows. After setting up the model in Section 2, we establish in Section 3 the equilibrium under both symmetric and asymmetric information conditions, and show that imitation takes place in equilibrium only under asymmetric information. Section 4 discusses the effects of stronger IPR enforcement on entry scale, social welfare, and a multinational's profits and innovation incentive. Section 5 concludes the paper.

\section{Model Set-up}

We consider a two-period model in which a multinational $(M)$ from a developed country has to decide whether and how to bring its product to a developing country. The quality of its product is either high or low, such that $M \in\left\{M^{h}, M^{l}\right\}$. The developing country comprises a continuum of regions, each forming a separate market which is referred to as a segment. Each segment is inhabited by a unit mass of consumers who demand $y_{t}$ units of the product in period $t(t=1,2)$. We normalize $y_{1} \equiv 1$ and $y_{2} \equiv y$ to reduce notation, and assume a growing economy, where $y>1$, for reasons that will become clear later in the paper. We denote by $u^{j}(i)$ the willingness to pay of the consumers in segment $i$ for a unit of a product of quality $j \in\{h, l\}$ with $u^{h}(i)>u^{l}(i)$. Segments differ in consumers' willingness to pay and are indexed such that $u^{j}(i)$ decreases in $i$. Let $\delta$ be the time discount factor.

In each period, $M$ can enter a segment through either direct investment $(k)$ or licensing $(s)$. The two entry modes differ in both the quality provided and cost structure. Direct investment delivers $M$ 's true quality, whereas licensing always delivers low quality because of local licensees' limited technological 
capacity. Direct investment requires, in each period, a country-wide setup cost $f$ and a marginal cost $c_{k}$, which is assumed to be type-independent. ${ }^{3}$ Licensing requires a smaller setup cost, which is normalized to zero, but a larger marginal cost because $M$ has to use extra resources to manage its licensee, an independent entity. Let $c^{j}$ be $M^{j}$ 's marginal cost of licensing for $j \in\{h, l\}$. We assume the high type's licensing cost to be greater than the low type's $\left(c^{h}>c^{l}>c_{k}\right)$ for the following reason. To prevent its licensee from stealing its technology, $M$ has to mask it during licensing. With better technology, $M^{h}$ stands to lose more from leaking its know-how than $M^{l}$ does, and hence is willing to incur a greater cost in masking. ${ }^{4}$

There are numerous identical domestic firms in each segment. A domestic firm can imitate $M$ 's technology at $\operatorname{cost} c$ and deliver a low quality product. We assume that such imitation is possible even in segments the multinational has chosen not to enter. To ensure that we do not trivialize the welfare implications of our analysis, we assume that although both modes offer a low-quality product, imitation is (weakly) less efficient than licensing: $c \geq c^{h}$. The strength of IPR enforcement is represented by $\gamma$, the probability that an imitator will be prosecuted at the end of each period. Once caught out, the imitator must compensate $M$ with its sales revenue. ${ }^{5}$ In our main analysis we assume that the strength of IPR enforcement remains the same over the two periods, an assumption that will be relaxed later.

The timing of the game and the information structure are as follows. In the first period, the multinational chooses whether to enter each segment, and, if it does so, whether to enter through licensing or investment. If it chooses licensing, it makes a take-it-or-leave-it offer to a randomly chosen domestic firm ( $M$ has all of the bargaining power because of the large number of identical domestic firms). If the offer is accepted, the licensee is entitled to use $M$ 's technology at a fee to supply the product in that particular segment. If the offer is rejected, $M$ does not enter that segment. In each segment, including those that the multinational has chosen not to enter, domestic firms can always engage in imitation. All imitators and the multinational's legal operation, if any, compete à la Bertrand in each segment. In the second period, $M$ must make a new decision regarding investment or licensing. The two periods differ in market size, as captured by $y$, and in consumers' belief concerning the multinational's type. We assume that consumers can distinguish between imitators and the multinational. However, they cannot directly observe product quality or $M$ 's type. ${ }^{6}$ At the beginning of the first period, consumers' a priori belief is that $M=M^{h}$ with probability $\rho_{1}$. By the end of that period, consumers observe both $M$ 's entry mode (licensing or investment) in their own segment and its entry scale (i.e., the number of segments entered by $M)$ through each mode in the entire country. ${ }^{7}$ This information allows consumers to update their beliefs at the beginning of the second period, $\rho_{2}$. Finally, we assume that imitators have the same information

\footnotetext{
${ }^{3}$ As explained later (footnote 9 ), our analysis remains qualitatively the same even when $c_{k}$ is type-dependent.

${ }^{4}$ This idea is formalized in our working paper (Che et al., 2012).

${ }^{5}$ We assume that IPR are enforced even in the segments the multinational has not entered. Note that a convicted offender may not always make the required compensation payment in a country with weak IPR enforcement. In this regard, $\gamma$ should be interpreted as the probability that a local copycat is caught and actually pays the compensation.

${ }^{6}$ This assumption can be relaxed to allow consumers to have a chance to observe product quality at the end of the first period, but the results remain qualitatively unchanged (Che et al., 2012).

${ }^{7}$ Consumers can observe the entry mode and scale because the legal operations of a multinational constitute public information.
} 
structure as consumers.

\section{The Signaling Equilibrium}

\subsection{Multinational's payoff}

In period $t$ and segment $i$, if an imitator is able to sell its product at price $p$, its expected payoff is $(1-\gamma) p-c$. Competition among imitators drives the price to

$$
p \equiv \frac{c}{1-\gamma}
$$

Knowing that imitators can produce only a low-quality product, consumers in segment $i$ will buy from an imitator only if $u^{l}(i) \geq p$. Therefore, imitation is feasible only in segments $i \leq x$, where $x$ is determined by

$$
u^{l}(x) \equiv p
$$

$x$ is the index of the marginal segment in which domestic firms are indifferent between imitating and not imitating. Slightly abusing the notation, we also use $x$ to denote the scale of potential imitation. Note that $x$ decreases in $\gamma$ : strengthening IPR enforcement reduces the potential scale of imitation.

If $M$ enters segment $i \leq x$ with an investment (after having sunk setup cost $f$ ), it faces competition from imitators. Consumers in segment $i$ are willing to pay up to

$$
u^{\rho_{t}}(i)=\rho_{t} u^{h}(i)+\left(1-\rho_{t}\right) u^{l}(i)
$$

for $M$ 's product supplied through investment when their belief is $\rho_{t}$. As $M$ enjoys both a cost advantage $\left(c_{k}<c\right)$ and quality premium $\left(u^{\rho_{t}}(i) \geq u^{l}(i)\right)$, it can charge a price that is sufficiently low to fend off imitators in the Bertrand competition. This means that $M$ will set its price $p$ such that $u^{\rho_{t}}(i)-p_{k}=$ $u^{l}(i)-p$, or $p_{k}=u^{\rho_{t}}(i)-u^{l}(i)+p$, and its investment profit in segment $i \leq x$ will thus be

$$
y_{t}\left[u^{\rho_{t}}(i)-u^{l}(i)+p-c_{k}\right]
$$

If $M$ enters segment $i \leq x$ through licensing, its licensee will have to charge $p$ to fight off competition from imitators. The licensee thus will earn $y_{t} p$ from licensing. If the licensee does not accept the license offer, it has the option to become an imitator and earn zero payoff. Thus, $M$ will set the licensing fee at $y_{t} p$ and offer the license to a random domestic firm, which will accept the offer. Accordingly, $M$ 's licensing profit in segment $i \leq x$ will be

$$
y_{t}\left(p-c^{j}\right)
$$

Should $M$ decide to withhold from entering a segment $i \leq x$, imitation will take place, and $M$ 's expected payoff will be $y_{t} \gamma p$.

In segment $i>x$, there is no competition from imitators. Thus, the price in segment $i$ is $u^{\rho_{t}}(i)$ for investment and $u^{l}(i)$ for licensing, and $M$ 's profit is

$$
y_{t}\left(u^{\rho_{t}}(i)-c_{k}\right)
$$


under direct investment and

$$
y_{t}\left(u^{l}(i)-c^{j}\right)
$$

under licensing. If $M$ withholds in segment $i$, it receives nothing from this segment.

The following table summarizes $M^{j}$ 's payoff per unit of market size in segment $i$ and period $t$. The multinational's total profit (excluding fixed cost $f$ in the case of investment) is this per-unit payoff multiplied by market size $y_{t}$. As previously noted, the two periods differ in $y_{t}$ and possibly $\rho_{t}$.

Table 1: $M^{j}$ 's payoff per unit of market size in segment $i$ and period $t$

\begin{tabular}{|c|c|c|}
\hline \multirow{2}{*}{} & \multicolumn{2}{|c|}{ segment } \\
\cline { 2 - 3 } & $i \leq x$ & $i>x$ \\
\hline investment $(k)$ & $u^{\rho_{t}}(i)-u^{l}(i)+\frac{c}{1-\gamma}-c_{k}$ & $u^{\rho_{t}}(i)-c_{k}$ \\
\hline licensing $(s)$ & $\frac{c}{1-\gamma}-c^{j}$ & $u^{l}(i)-c^{j}$ \\
\hline withholding/imitation $(x)$ & $\frac{\gamma c}{1-\gamma}$ & 0 \\
\hline
\end{tabular}

\subsection{Entry decision}

Denote by $\left\{\kappa_{t}^{j}, \sigma_{t}^{j}\right\}$ the entry choice made by $M^{j}$ in period $t$, where $\kappa_{t}^{j}$ is the measure of segments entered through direct investment and $\sigma_{t}^{j}$ is the measure entered through licensing. Denote by $\Pi_{t}^{j} M^{j}{ }^{\prime} \mathrm{s}$ total profit in period $t$. The entry problem faced by the multinational differs between the two periods, as the first-period entry serves the additional function of signaling.

- The second period

In the second period, the trade-off between direct investment and licensing is the following. Direct investment requires a setup cost, $f$. However, in every segment, investment dominates licensing, as $c_{k}<$ $c^{l}<c^{h}$ and $u^{\rho_{2}}(i) \geq u^{l}(i)$ for all $i$. Therefore, investment and licensing cannot coexist.

Suppose that $M^{j}$ chooses licensing. Because the licensing payoff decreases in $i$, licensing yields a non-negative profit in segment $i \leq s^{j}$, where $s^{j}$ is defined by

$$
u^{l}\left(s^{j}\right) \equiv c^{j}
$$

As $c^{j}<\frac{c}{1-\gamma}$, we have $s^{j}>x$. Note that $s^{j}$ depends on $M$ 's type owing to the difference in licensing cost, and $s^{j}$ is the same for both periods. Define

$$
\pi_{s}^{j} \equiv \int_{0}^{x}\left(\frac{c}{1-\gamma}-c^{j}\right) d i+\int_{x}^{s^{j}}\left(u^{l}(i)-c^{j}\right) d i
$$

as $M^{j}$ 's payoff per unit of market size under licensing. Then $M^{j}$ 's second-period profit is $\Pi_{2, s}^{j}=y \pi_{s}^{j}$.

Suppose that $M^{j}$ chooses investment. Similar to the foregoing analysis, direct investment generates a non-negative profit in segment $i \leq k^{\rho_{2}}$, where $k^{\rho_{2}}$ is defined by

$$
u^{\rho_{2}}\left(k^{\rho_{2}}\right) \equiv c_{k}
$$


Because $c_{k}<\frac{c}{1-\gamma}$ and $u^{\rho_{2}}(i) \geq u^{l}(i)$, we have $k^{\rho_{2}}>x$. Note that $k^{\rho_{2}}$ depends on $\rho_{2}$ but not on $j$ (i.e., the true identity of $M$ for a given $\rho_{2}$ ). Define

$$
\pi_{k}^{\rho_{2}} \equiv \int_{0}^{x}\left(u^{\rho_{2}}(i)-u^{l}(i)+\frac{c}{1-\gamma}-c_{k}\right) d i+\int_{x}^{k^{\rho_{2}}}\left(u^{\rho_{2}}(i)-c_{k}\right) d i
$$

as $M$ 's payoff per unit of market size under investment. Then $M$ 's second-period profit is $\Pi_{2, k}^{\rho_{2}}=y \pi_{k}^{\rho_{2}}-f$.

The second-period entry problem for $M^{j}$ is therefore reduced to a choice between direct investment and licensing: $\max \left\{\Pi_{2, k}^{\rho_{2}}, \Pi_{2, s}^{j}\right\}$.

- The first period

The first-period entry profile $\left\{\kappa_{1}, \sigma_{1}\right\}$ affects consumers' beliefs in the second period. Their offequilibrium beliefs are assumed to follow the intuitive criterion (Cho and Kreps, 1987). $M^{j}$ 's first-period choice is therefore

$$
\max _{\left\{\kappa_{1}^{j}, \sigma_{1}^{j}\right\}} \Pi_{1}^{j}\left(\left\{\kappa_{1}^{j}, \sigma_{1}^{j}\right\}\right)+\delta \max \left\{\Pi_{2, k}^{\rho_{2}\left(\left\{\kappa_{1}, \sigma_{1}\right\}\right)}, \Pi_{2, s}^{j}\right\} .
$$

For signaling purposes, $M^{j}$ may choose investment and licensing simultaneously in the first period, in which case we assume for the sake of simplicity that its investments are in lower-indexed segments: investment in segments $i \in\left[0, \kappa_{1}^{j}\right]$ and licensing in segments $i \in\left(\kappa_{1}^{j}, \kappa_{1}^{j}+\sigma_{1}^{j}\right]{ }^{8}$ A perfect Bayesian equilibrium is a pair of $\left\{\left\{\kappa_{1}^{h}, \sigma_{1}^{h}\right\},\left\{\kappa_{1}^{l}, \sigma_{1}^{l}\right\}\right\}$ that solves (5) for $j \in\{h, l\}$ simultaneously.

\subsection{Equilibrium under symmetric information}

As a benchmark, we first consider the case of symmetric information, i.e., $M$ 's type is known to consumers. As consumers' willingness to pay and entry cost do not change over time, the entry scale of any given entry mode must be the same across the two periods: $\kappa_{1}^{j}=\kappa_{2}^{j}=k^{j}$ and $\sigma_{1}^{j}=\sigma_{2}^{j}=s^{j}$, where $k^{j}$ is defined by

$$
u^{j}\left(k^{j}\right) \equiv c_{k}
$$

As before, because $c_{k}<\frac{c}{1-\gamma}$ and $u^{j}(i) \geq u^{l}(i)$, we have $k^{j}>x$.

Because the second-period profit is independent of $\left\{\kappa_{1}^{j}, \sigma_{1}^{j}\right\}$, M's first-period entry simply maximizes the profit in that period. As in the second period, investment and licensing do not coexist in period 1 and, hence, the entry problem in this period is again reduced to a choice between direct investment and licensing. The equilibrium entry mode, however, may differ between the two periods, as the market size grows. Define $\pi_{k}^{j}$ as $M^{j}$ 's investment payoff per unit of market size under symmetric information:

$$
\pi_{k}^{j} \equiv \int_{0}^{x}\left(u^{j}(i)-u^{l}(i)+\frac{c}{1-\gamma}-c_{k}\right) d i+\int_{x}^{k^{j}}\left(u^{j}(i)-c_{k}\right) d i .
$$

\footnotetext{
${ }^{8}$ This assumption helps to simplify the exposition of our analysis. Otherwise, $M$ 's entry may consist of greater dimensions (moving down the segments, the entry may be investment, licensing, then investment again and licensing again, etc.), which would greatly expand $M$ 's strategy space and complicate our analysis without yielding any new insights. Note that the assumed behavior would be optimal if $u^{h}(i)$ declines with $i$ faster than $u^{l}(i)$. To see why, suppose that $M$ invests in segment $i$ but licenses in segment $i^{\prime}<i$. Let $M$ swap the mode of entry between the two segments. As the entry scale of each mode remains the same, the swap does not affect consumers' posterior belief, $\rho_{2}$, and hence $M$ 's second period profit. Nevertheless, its first-period profit changes by the amount of $\left[\rho_{1} u^{h}\left(i^{\prime}\right)+\left(1-\rho_{1}\right) u^{l}\left(i^{\prime}\right)+u^{l}(i)\right]-\left[\rho_{1} u^{h}(i)+\left(1-\rho_{1}\right) u^{l}(i)+u^{l}\left(i^{\prime}\right)\right]=\rho_{1}\left[u^{h}\left(i^{\prime}\right)-u^{h}(i)\right]-\rho_{1}\left[u^{l}\left(i^{\prime}\right)-u^{l}(i)\right]$, which is positive given the assumption that $u^{h}(i)$ declines with $i$ faster than $u^{l}(i)$. Thus, $M$ is better off with the swap.
} 
In the first period, the profit is $\pi_{k}^{j}-f$ for direct investment and $\pi_{s}^{j}$ for licensing. The corresponding profits in the second period are $y \pi_{k}^{j}-f$ and $y \pi_{s}^{j}$ respectively.

Lemma 1 Suppose that

$$
\pi_{k}^{h}<f<y\left(\pi_{k}^{h}-\pi_{s}^{h}\right)
$$

Under symmetric information, both types of $M$ license in the first period. In the second period, $M^{h}$ chooses direct investment, whereas $M^{l}$ chooses direct investment if $f \leq y\left(\pi_{k}^{l}-\pi_{s}^{l}\right)$ and licensing otherwise.

Condition (8) characterizes a growing economy, the size of which is too small in the first period for investment to be profitable even for $M^{h}$, but becomes much larger in the second period, such that $M^{h}$ finds investment more profitable than licensing. To simplify the exposition and focus on our scenario of interest, we assume throughout the remainder of the paper that condition (8) holds. Because $\pi_{k}^{l}<\pi_{k}^{h}$, if investment is unprofitable for $M^{h}$ in the first period, it must also be unprofitable for $M^{l}$. Note that because $M$ always operates beyond the marginal segment in which imitators are indifferent between entering and not entering, imitation does not take place in equilibrium.

We now consider the effects of strengthening IPR enforcement under symmetric information. For a given entry mode, $M$ 's entry scale is determined by its zero-profit condition and is independent of $\gamma$. In every segment that $M$ enters, the social benefit and social cost of supplying $M$ 's product are also independent of $\gamma$. The presence of imitators merely reduces the rent that $M$ enjoys. As the reduction in $M$ 's rent (which equals $\left.u^{l}(i)-\frac{c}{1-\gamma}\right)$ is the same whether it enters through investment or licensing, $\pi_{k}^{j}-\pi_{s}^{j}$ is independent of $\gamma$ for either type of multinational. Therefore, IPR strength does not affect the equilibrium choice of entry mode. In sum, stronger IPR enforcement does not change social welfare.

$M$ 's profits, however, are improved by stronger IPR enforcement:

$$
\begin{aligned}
\frac{d \pi_{k}^{j}}{d \gamma} & =\frac{d \pi_{s}^{j}}{d \gamma}=\int_{0}^{x} \frac{c}{(1-\gamma)^{2}} d i+\left(p(\gamma)-u^{l}(x)\right) \frac{d x}{d \gamma} \\
& =\int_{0}^{x} \frac{c}{(1-\gamma)^{2}} d i
\end{aligned}
$$

which is positive when $x>0$. Stronger IPR enforcement has two effects. First, it raises imitators' break-even price $p(\gamma)$, which allows $M^{j}$ to charge consumers a higher price. Second, it reduces the scale of potential imitation $(x)$. The second effect is muted, however, because in the marginal segment in which imitators are indifferent between entering and not entering, their break-even price equals consumers' willingness to pay, $p(\gamma)=u^{l}(x)$, and thus $M^{j}$ loses no profits because of the threat of imitation.

Proposition 1 Under symmetric information, IPR violations never take place in equilibrium. Stronger $I P R$ enforcement does not affect social surplus or entry choice, but (weakly) improves the multinational's profits.

The last property, i.e., that the multinational's profits increase with IPR strength, justifies the conventional wisdom in an environment in which information is symmetric. It is worth emphasizing that no 
matter how weak the IPR enforcement is, imitation will never take place in equilibrium in such an environment. With a cost advantage and quality premium (when $M^{h}$ enters through direct investment), $M$ is able to outprice imitators through competition. The absence of equilibrium imitation arises not from the nature of Bertrand competition, but rather from the numerous copycats competing with one another. Our result holds even under Cournot competition. The consequences of weak IPR enforcement lie not in any observed IPR violations but in $M$ 's lower profits resulting from the threat of potential imitation.

\subsection{Equilibrium under asymmetric information}

We now turn to the main focus of this paper: reputation concerns arising from information asymmetry. A better reputation enables a multinational to charge a higher price when it enters through direct investment in the second period. As a result, both multinational types may try to establish a better reputation by carefully choosing their first-period entry profile. In particular, $M^{l}$ may attempt to mimic $M^{h}$ 's entry choice, and in response $M^{h}$ may adopt an entry profile that distances it from $M^{l}$.

$M^{l}$ will be discouraged from mimicking $M^{h}$ s entry profile if being itself produces a better payoff:

$$
\pi_{s}^{l}+\delta \max \left\{y \pi_{k}^{l}-f, y \pi_{s}^{l}\right\} \geq \Pi_{1}^{l}\left(\left\{\kappa_{1}^{h}, \sigma_{1}^{h}\right\}\right)+\delta\left(y \pi_{k}^{h}-f\right) .
$$

Note that the second term on the right-hand side, $\delta\left(y \pi_{k}^{h}-f\right)$, is the low type's second-period payoff when it successfully convinces consumers that it is a high type. The following condition, which we assume throughout the rest of the paper, ensures that it is feasible for $M^{h}$ to distance itself from $M^{l}$ :

$$
\pi_{s}^{l}-\gamma x p \geq \delta y\left(\pi_{k}^{h}-\pi_{k}^{l}\right),
$$

where $\gamma x p=\int_{0}^{x} \gamma p d i$ is the multinational's payoff should it withdraw completely. The right-hand side of (10) is the upper bound of the return that $M^{l}$ obtains by successfully convincing consumers that it is $M^{h}$. The left-hand side is the maximal cost that $M^{h}$ can impose on $M^{l}$ by choosing to withhold its entry completely in the first period. When (10) holds, it is feasible for $M^{h}$ to choose an entry profile (by withholding from enough segments) in period 1 that $M^{l}$ will find unprofitable to mimic.

Given such feasibility, we now turn to $M^{h}$ 's incentive to separate itself from $M^{l}$. With a particular entry profile $\left\{\kappa_{1}, \sigma_{1}\right\}$ and posterior belief $\rho_{2}, M^{j}$ 's two-period total profit is

$$
\Pi^{j}\left(\left\{\kappa_{1}, \sigma_{1}\right\}, \rho_{2}\right) \equiv \Pi_{1}^{j}\left(\left\{\kappa_{1}, \sigma_{1}\right\}\right)+\delta \max \left\{y \pi_{k}^{\rho_{2}}-f, y \pi_{s}^{j}\right\} .
$$

The marginal return to a better reputation is $\frac{\partial \Pi^{j}}{\partial \rho_{2}}$. When $\rho_{2}$ is sufficiently large, both types undertake direct investment in the second period, in which case they enjoy the same marginal return:

$$
\frac{\partial \Pi^{h}}{\partial \rho_{2}}=\frac{\partial \Pi^{l}}{\partial \rho_{2}}=\delta y \frac{\partial \pi_{k}^{\rho_{2}}}{\partial \rho_{2}} .
$$

Because direct investment in the first period gives the two types the same payoff, the marginal cost of reputation through period-1 investment is the same for both:

$$
\frac{\partial \Pi^{h}}{\partial \kappa_{1}}=\frac{\partial \Pi^{l}}{\partial \kappa_{1}} .
$$


The marginal cost of reputation through licensing differs, however:

$$
\frac{\partial \Pi^{j}}{\partial \sigma_{1}}= \begin{cases}c-c^{j}>0, & \text { if } \sigma_{1} \leq x ; \\ u^{l}\left(\sigma_{1}\right)-c^{j} \geq 0, & \text { if } \sigma_{1} \in\left(x, s^{j}\right] ; \\ u^{l}\left(\sigma_{1}\right)-c^{j}<0, & \text { if } \sigma_{1}>s^{j} .\end{cases}
$$

In particular, $c^{h}>c^{l}$ implies that

$$
\frac{\partial \Pi^{h}}{\partial \sigma_{1}}<\frac{\partial \Pi^{l}}{\partial \sigma_{1}}, \forall \sigma_{1}
$$

$M^{h}$ is able to command an advantage over $M^{l}$ in paying for a better reputation in two situations. The first is when $\sigma_{1} \in\left(s^{h}, s^{l}\right)$, in which case a marginal reduction in licensing scale benefits $M^{h}$ but hurts $M^{l}$. The second is when $\sigma_{1} \leq s^{h}$, in which case a marginal reduction in licensing scale costs $M^{h}$ less than it costs $M^{l}$.

The foregoing discussion establishes the single-crossing property: there exists $\sigma_{1} \leq s^{l}$, such that maintaining a better reputation through a reduction in licensing scale is less costly for $M^{h}$ than for $M^{l}$. Given the feasibility condition (10), there therefore exists $s^{*}>0$, such that (9) holds in equality at $\left\{\kappa_{1}^{h}, \sigma_{1}^{h}\right\}=\left\{0, s^{*}\right\}$ :

$$
\pi_{s}^{l}-\Pi_{1}^{l}\left(\left\{0, s^{*}\right\}\right) \equiv \Delta,
$$

where

$$
\Delta \equiv \delta\left(y \pi_{k}^{h}-f\right)-\delta \max \left\{y \pi_{k}^{l}-f, y \pi_{s}^{l}\right\}
$$

is the return to $M^{l}$ from mimicking $M^{h}$. In (11) and (12), $\pi_{s}^{l}$ is given by (2), $\pi_{k}^{j}$ is given by (7), and

$$
\Pi_{1}^{l}\left(\left\{0, s^{*}\right\}\right)= \begin{cases}\int_{0}^{x}\left(p(\gamma)-c^{l}\right) d i+\int_{x}^{s^{*}}\left(u^{l}(i)-c^{l}\right) d i & \text { for } s^{*}>x \\ \int_{0}^{s^{*}}\left(p(\gamma)-c^{l}\right) d i+\int_{s^{*}}^{x} \gamma p(\gamma) d i & \text { for } s^{*} \leq x\end{cases}
$$

We are now ready to present one of the key results of this paper.

Proposition 2 There exists a unique and separating equilibrium, where, in the first period, $M^{l}$ licenses in $s^{l}$ segments, and $M^{h}$ licenses in $\min \left\{s^{*}, s^{h}\right\}$ segments.

The formal proof of Proposition 2 is relegated to the Appendix, but its intuition can be simply explained. Because $M^{h}$ and $M^{l}$ differ only in their licensing costs, $M^{h}$ is unable to distance itself from $M^{l}$ via direct investment alone. Because investment is unprofitable in the first period, any combination of investment and licensing is dominated by a combination of withholding and licensing. No pooling equilibrium exists because by choosing a licensing scale below $s^{l}, M^{h}$ commands an advantage over $M^{l}$ in paying for a better reputation. In a separating equilibrium, knowing that its type will be fully revealed in the second period, $M^{l}$ enters fully (i.e., $s^{l}$ segments) in period 1 , as it does in the benchmark case. To separate itself from $M^{l}, M^{h}$ chooses $s^{*}$ when $s^{*}<s^{h}$. If $s^{*} \geq s^{h}, M^{h}$ will simply choose $\left\{0, s^{h}\right\}$ to maximize its first-period profit, as $M^{l}$ will make no attempt to mimic $M^{h}$ 's entry profile. ${ }^{9}$

From Proposition 2, it is straightforward to derive the following result.

\footnotetext{
${ }^{9}$ For simplicity we assume that $c_{k}$ does not depend on $M$ 's type, although the results remain the same even if it does. In
} 
Proposition 3 IPR violation takes place in equilibrium if and only if $M=M^{h}$ and $s^{*}<x$, and it takes place in period 1 in segments $i \in\left[s^{*}, x\right]$.

Recall that imitation is never observed when information is symmetric. Proposition 3 highlights the reason for equilibrium imitation: the strategic withholding of entry by the multinational in an attempt to maintain its reputation, which in turn allows imitators to survive in the market. A unique feature of this paper is that IPR violations take place in equilibrium despite the possibility of licensing. The existing literature generates equilibrium imitation by assuming away the possibility of licensing, which we consider unrealistic. By introducing reputation concerns, we are able to show how IPR violations may emerge in equilibrium in an environment that allows the multinational to license to potential imitators.

For the remainder of the paper, we refer to the case of $s^{*}>x$ as a non-imitation equilibrium and to that of $s^{*} \leq x$ as an imitation equilibrium. We first identify the factors that affect the extent of IPR violations. Suppose that $u^{j}(i)$ can be shifted up by parameter $\theta^{j}$ for $j \in\{h, l\}$ for all $i$ and that $\delta=\frac{1}{1+r}$ is the discount factor corresponding to an interest rate $r$. Condition (11) reveals the following.

Proposition 4 In an imitation equilibrium, the scale of IPR violations increases in $y$ and $\theta^{h}$ and decreases in $r$ and $\theta^{l}$.

Proposition 4 suggests that more IPR violations will be observed in an economy with a higher growth rate, lower interest rate, or larger quality premium (higher $\theta^{h}$ or lower $\theta^{l}$ ). A rapidly growing economy that expands the product market substantially in the future increases the return to a good reputation, thus enhancing the incentive for $M^{l}$ to mimic $M^{h}$ unless $M^{h}$ withdraws its entry further to increase the cost of mimicking. As $M^{h}$ withdraws further, it leaves more room for IPR violations. Likewise, a lower interest rate in a growing economy increases the present discounted value of a good reputation, forcing $M^{h}$ to further withdraw its entry to prevent $M^{l}$ from mimicking it. A quality premium does not increase IPR violations because imitated products can be priced at a higher amount. In our model, imitators are assumed to be competitive, and as a result they price at their marginal cost (adjusted by the probability of IPR enforcement) without any direct effect of a higher quality premium. Instead, a larger quality premium enhances the return to a good reputation, which, as in the case of a higher growth rate or lower interest rate, induces $M^{h}$ to further withdraw its entry, leaving more room for imitation.

equilibrium $M$ enters in the first period through licensing such that the investment $\operatorname{cost} c_{k}$ does not matter. In the second period, $M$ 's type is fully revealed through signaling, and thus $c_{k}$ affects only $M$ 's payoff without qualitatively changing any results reported in the propositions. If $c_{k}$ depends on $M$ 's type, $M$ may signal its type in the first period through investment rather than withholding licensing scale. However, as noted, withholding in a given segment (which gives $M$ a positive payoff) always dominates investment in that segment (which gives $M$ a negative payoff because of the limited market size in period 1). Finally, in the incentive-compatibility condition (equations (11) and (12)), the expression of $\Delta$ will change if $c_{k}$ is typedependent, but $\Delta$ will continue to be independent of enforcement strength $\gamma$, and thus all of the comparative static results remain unchanged. 


\section{The Effects of Strengthening IPR Enforcement}

Having established the equilibrium under asymmetric information, we now examine the effects of strengthening IPR enforcement (i.e., a larger $\gamma$ ) on $M$ 's entry scale and profits and social welfare. We begin with the following observations. First, because IPR enforcement does not alter consumers' valuation of the multinational's product, it exerts its influence only through the operating decisions of the two types of $M$ and their imitators. Second, in a separating equilibrium, the types are fully revealed in the second period. Thus, as discussed in the symmetric information case, the second-period entry decisions of both types of $M$ are independent of $\gamma$. Third, the first-period choice made by $M^{l}$ is also unaffected. Only the first-period licensing scale of $M^{h}$ is subject to change. Fourth, because $x<\min \left\{s^{l}, k^{h}, k^{l}\right\}$ and stronger enforcement in the second period exerts an influence only through $x$, the marginal gain of reputation, $\Delta$, is independent of $\gamma$. This last observation implies that the change in $M^{h}$ 's first-period licensing scale must come from the marginal cost of reputation, i.e., the left-hand side of equation (11).

Consider first a non-imitation equilibrium $\left(s^{*}>x\right)$, in which case equation ( 11) becomes

$$
\int_{s^{*}}^{s^{l}}\left(u^{l}(i)-c^{l}\right) d i=\Delta
$$

Neither side of the equation involves $\gamma$, and thus equilibrium entry scale $s^{*}$ does not depend on $\gamma$. Because stronger enforcement makes it more costly for domestic firms to imitate $M$ 's product, the imitators' price $(p)$ is higher and the imitation scale $(x)$ is smaller. These two effects affect $M^{h}$ and $M^{l}$ symmetrically when $s^{*}$ is beyond $x$, and thus the incentive compatibility constraint remains intact. As $x$ retreats, inequality $s^{*}>x$ continues to hold, so $M^{h}$ and $M^{l}$ still operate beyond $x$. The retreat of $x$ will therefore have no effect on $M$ 's profit at the margin, but its profits inside the margin will increase owing to a higher $p$, as in the case of symmetric information. Given that the entry scale of both types of $M$ remains the same in both periods and is larger than that of potential imitation, it is straightforward to conclude that social welfare must also remain the same.

Proposition 5 In a non-imitation equilibrium, stronger IPR enforcement increases the profits of both $M^{h}$ and $M^{l}$, but has no effect on their entry decisions or social welfare.

Now consider an imitation equilibrium $\left(s^{*} \leq x\right)$, in which case (11) becomes

$$
\int_{s^{*}(\gamma)}^{x}\left(c-c^{l}\right) d i+\int_{x}^{s^{l}}\left(u^{l}(i)-c^{l}\right) d i=\Delta .
$$

Because $x$ is a function of $\gamma, s^{*}$ must also depend on $\gamma$. Strengthening IPR enforcement has two asymmetric effects on $M^{h}$ and $M^{l}$, as the former operates inside the margin in which imitators operate $\left(s^{*}<x\right)$, whereas the latter operates beyond that margin $\left(s^{l}>x\right)$. The rising imitation price allows $M^{l}$ to raise its payoff dollar by dollar in segment $i \in\left(s^{*}, x\right]$, but allows $M^{h}$ to increase its payoff only through successful litigation, i.e., only with probability $\gamma$. A smaller imitation scale does not affect $M^{l}$ 's payoff, but it reduces 
$M^{h}$ 's, as $M^{h}$ collects compensation from fewer segments in which imitation takes place. Hence stronger IPR enforcement increases $M^{l}$ 's profits more than $M^{h}$ 's (if $M^{h}$ 's profits increase at all). As a result, the incentive compatibility constraint must become slack, allowing $M^{h}$ to expand $s^{*}$. Formally, we differentiate both sides of (13) with respect to $\gamma$ to get

$$
\left(c-c^{l}\right) \frac{d s^{*}}{d \gamma}+\left(u^{l}(x)-c\right) \frac{d x}{d \gamma}=0 .
$$

Because $u^{l}(x)=p>c$ and $\frac{d x}{d \gamma}<0$, we have

$$
\frac{d s^{*}}{d \gamma}>0
$$

Proposition 6 (Entry Scale) In an imitation equilibrium, stronger IPR enforcement increases $M^{h}$ 's first-period entry scale, but has no effect on $M^{l}$ 's first-period entry scale or either type's second-period entry decision.

We turn next to social welfare. An increase in $s^{*}$ is accompanied by a decrease in $x$ : some of the segments previously served by imitators are now served by legally licensed products from $M^{h}$, whereas others are no longer served at all. The first change brings an efficiency gain, as legal licensing is less costly than imitation. The second change, however, results in an efficiency loss. Imitation creates a social surplus even though it violates $M$ 's property rights. Under symmetric information, imitation does not take place in equilibrium, and a decrease in $x$ merely reduces the competition $M$ faces without any effect on social welfare. Under asymmetric information, in contrast, $M^{h}$ chooses not to serve certain segments. In an imitation equilibrium, some of these unserved segments are served by imitators, which represents a social gain. A smaller $x$ reduces this social gain.

To determine the net effect on social welfare, let $W_{1}^{h}$ denote the first-period social welfare for $M^{h}$ :

$$
W_{1}^{h}=\int_{0}^{s^{*}(\gamma)}\left(u^{l}(i)-c^{h}\right) d i+\int_{s^{*}(\gamma)}^{x(\gamma)}\left(u^{l}(i)-c\right) d i
$$

Making use of (14) we obtain

$$
\begin{aligned}
\frac{d W_{1}^{h}}{d \gamma} & =\left(c-c^{h}\right) \frac{d s^{*}}{d \gamma}+\left(u^{l}(x)-c\right) \frac{d x}{d \gamma} \\
& =\left(c^{l}-c^{h}\right) \frac{d s^{*}}{d \gamma}<0 .
\end{aligned}
$$

Therefore, the efficiency loss resulting from a smaller $x$ always outweighs the efficiency gain resulting from a larger $s^{*}$, and thus first-period social welfare decreases with $\gamma$ when $M=M^{h}$. Because IPR strength does not affect first-period welfare when $M=M^{l}$ or second-period welfare for both types, we conclude that the two-period total expected social welfare must decline.

Proposition 7 (Welfare) In an imitation equilibrium, strengthening IPR enforcement reduces social welfare. 
It is well-known that, holding constant a multinational's incentive to innovate, stronger IPR protection results in social welfare loss because it allows distortionary monopoly pricing. By assuming unit demand, this paper stays away from such an effect, and the welfare loss arises for an entirely different reason. From (14) and (15), we know that efficiency loss $u^{l}(i)-c$ equals the acquired incentive for $M^{l}$ to mimic $M^{h}$, whereas efficiency gain $c-c^{h}(i)$ is smaller than the acquired disincentive, $c-c^{l}(i)$, for $M^{l}$ not to mimic $M^{h}$, as $M^{h}$ faces a larger licensing cost. When IPR enforcement becomes stronger, $s^{*}$ must respond to the reduction in $x$ to keep the acquired incentive in balance with the acquired disincentive. Therefore, social welfare must decrease.

Finally, we analyze how better IPR enforcement influences a multinational's profits and hence its incentive to innovate. When $s^{*} \leq x, M^{l}$,s operating scale exceeds that of imitators in both periods, and thus stronger IPR enforcement raises $M^{l}$ 's profits, as in the benchmark case. Similarly, $M^{h}$ 's second-period profits also increase: $\frac{d\left(y \pi_{k}^{h}-f\right)}{d \gamma}=y \int_{0}^{x} \frac{c}{(1-\gamma)^{2}} d i>0 . M^{h}$ 's first-period profit is

$$
\Pi_{1}^{h}\left(\left\{0, s^{*}\right\}\right)=\int_{0}^{s^{*}(\gamma)}\left(p(\gamma)-c^{h}\right) d i+\int_{s^{*}(\gamma)}^{x(\gamma)} \gamma p(\gamma) d i .
$$

Differentiating this profit with respect to $\gamma$, we obtain

$$
\frac{d \Pi_{1}^{h}\left(\left\{0, s^{*}\right\}\right)}{d \gamma}=\left(c-c^{h}\right) \frac{d s^{*}}{d \gamma}+\int_{0}^{x} \frac{c}{(1-\gamma)^{2}} d i+\gamma p \frac{d x}{d \gamma} .
$$

This expression reveals three effects that stronger IPR enforcement has on $M^{h}$ 's first-period profit. First, it expands $s^{*}$, which allows $M^{h}$ to drive away imitators in some segments and collect social gain $c-c^{h}$ in each of these segments. Second, it raises the imitation price, and thus $M^{h}$ 's payoff, as $M^{h}$ will raise its own price in licensed segments and collect more compensation in segments in which imitation takes place. Third, it reduces $x$, which reduces the compensation that $M^{h}$ can collect through IPR litigation. Substituting (14) into the foregoing equation allows us to calculate the effect of stronger enforcement on $M^{h}$ 's total profits:

$$
\frac{d\left(\Pi_{1}^{h}\left(\left\{0, s^{*}\right\}\right)+\delta\left(y \pi_{k}^{h}-f\right)\right)}{d \gamma}=x p\left(\frac{1+\delta y}{1-\gamma}+\frac{c^{h}-c^{l}}{c-c^{l}} \frac{d \ln x}{d \ln \gamma}\right) .
$$

Proposition 8 (Profit) In an imitation equilibrium, stronger IPR enforcement increases the profits of $M^{l}$. It increases the profits of $M^{h}$ if and only if

$$
(1+\delta y) \frac{c-c^{l}}{c^{h}-c^{l}}+(1-\gamma) \frac{d \ln x}{d \ln \gamma}>0 .
$$

To better understand condition (16), note that

$$
(1-\gamma) \frac{d \ln x}{d \ln \gamma}=\frac{\gamma}{1-\gamma} \frac{c}{x u^{l^{\prime}}(x)},
$$

where $u^{l^{\prime}}(i) \equiv \frac{d u^{l}(i)}{d i}$. Therefore, we can further conclude the following.

Corollary In any imitation equilibrium, stronger IPR enforcement 


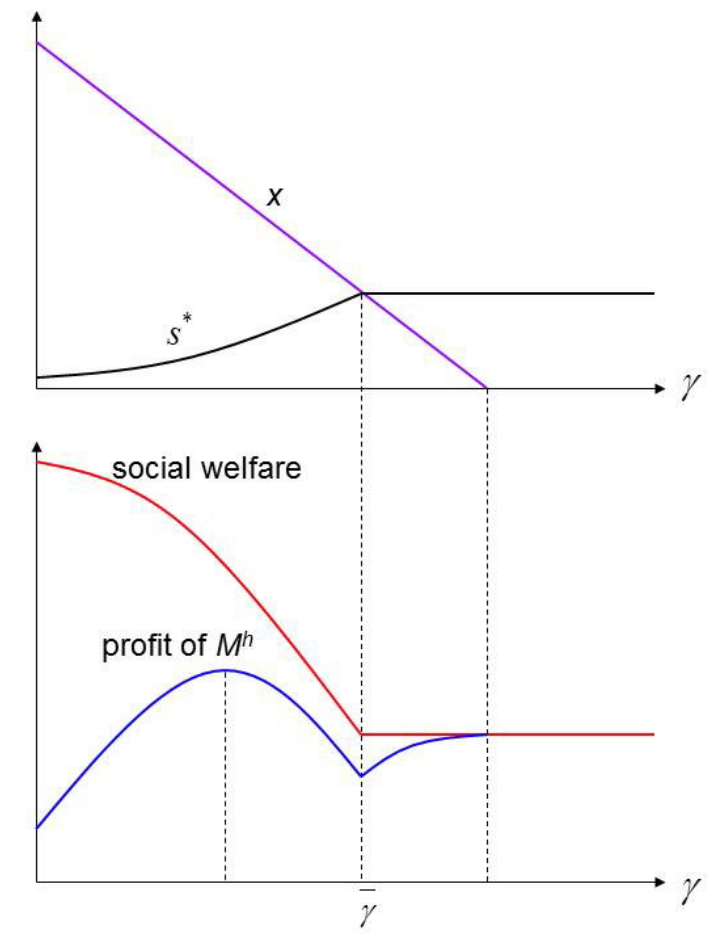

Figure 1: First-period entry scale, two-period profits, and social welfare when $M=M^{h}$ and $u^{l}(i)=b i^{-\alpha}$.

1) increases the profit of $M^{h}$ when $\gamma$ is sufficiently small, but

2) decreases the profit of $M^{h}$ for some positive $\gamma$ when $u^{l^{\prime}}(\cdot)$ is sufficiently small.

To illustrate this corollary, we consider utility function $u^{l}(i)=b i^{-\alpha}$, where $b$ is some positive constant and $\alpha>0$ measures the dispersion in willingness to pay across segments. A larger $\alpha$ corresponds to a more dispersed distribution. Should the willingness to pay be rooted in affordability, $\alpha$ also reflects income dispersion. Given that $u^{l}(x)=p$, we have $(1-\gamma) \frac{d \ln x}{d \ln \gamma}=-\frac{\gamma}{\alpha}$. Hence, condition (16) is reduced to

$$
(1+\delta y) \frac{c-c^{l}}{c^{h}-c^{l}}>\frac{\gamma}{\alpha},
$$

which holds when $\gamma$ is small, and does not hold when $\alpha$ is sufficiently small.

Figure 1 shows how, for $u^{l}(i)=b i^{-\alpha}, M^{h}$ 's first-period entry scale, two-period total profits and social welfare respond to changes in $\gamma$. Condition (14) reveals that imitation arises in equilibrium $\left(s^{*} \leq x\right)$ if and only if $\gamma$ is below some threshold, say, $\bar{\gamma}$. In such an equilibrium, $x$ declines with $\gamma$, whereas $s^{*}$ increases with it. Social welfare decreases with $\gamma$, and $M^{h}$ 's profit is inversely U-shaped. When $\gamma \geq \bar{\gamma}$, imitation does not take place in equilibrium $\left(s^{*} \geq x\right)$. In this region, $x$ continues to decline as $\gamma$ increases, but the profits earned by $M^{h}$ begin to increase with $\gamma$. At the same time, $s^{*}$ becomes independent of $\gamma$ and, as a result, social welfare remains constant. When enforcement becomes sufficiently strong, imitation is no longer feasible in any segment. A further strengthening of IPR enforcement has no effect whatsoever. 
Because $M$ faces no threats from local competition, its profit equals the social surplus.

The comparative statics discussed thus far (Propositions 5 through 8) offer a few interesting insights. First, they put into perspective the empirical observations that stronger IPR enforcement encourages multinationals' entry (Maskus and Penubarti, 1995; Smith, 2001; Branstetter et al., 2006; Ivus, 2010; Branstetter et al., 2011). Our analysis demonstrates that stronger IPR enforcement encourages the entry of multinationals only when IPR violations are observed in equilibrium.

Second, whenever such entry is expanded by stronger IPR enforcement, social welfare declines. Stronger enforcement exerts two effects on social welfare. By inducing more entry, it allows certain segments to be served more efficiently (through licensing rather than imitation). However, it also forces imitators to abandon certain segments. As explained earlier, the very reason that a multinational is induced to leave some segments unserved implies that the gain will be outweighed by the loss. This cautions welfare implications based on the aforementioned empirical observations.

Third, our analysis offers an alternative explanation for why stronger IPR enforcement may lead to efficiency loss ex post, that is, after a technology has been invented. It is well understood that IPR protection involves a social cost and that this cost arises because IPR protection allows the innovator to charge distortionary monopoly prices. This conventional channel of efficiency loss is removed from the present paper as we assume a perfectly inelastic demand. In this paper, the efficiency loss arises because stronger IPR enforcement reduces the total number of segments served (particularly those served by imitators). More fundamentally, the ex post efficiency loss stems from non-rivalry over knowledge: Once a knowledge has been invented, allowing it to be used by copycats in markets not served by its owner will create social gains, and forbidding such imitation constitutes a social loss. In the presence of reputation concerns, weak enforcement allows imitators to exploit such non-rivalry over knowledge; strong enforcement denies such a possibility.

Fourth, strengthened IPR enforcement does not always improve multinationals' ex ante incentives to innovate. As a multinational derives ex ante incentives from the profits it can earn ex post, Propositions 5 and 8 imply that better enforcement can have divergent effects on innovation for different types of multinational. Stronger enforcement always encourages the innovation of low-quality products, but it may discourage the innovation of high-quality products when the enforcement has reached a certain level. In this regard, the average quality of the technology transferred to a developing country may be lower, thus representing an ex ante efficiency loss from IPR improvement.

Although the foregoing discussion appears to portray rather grim prospects for IPR improvement in the presence of information asymmetry, there is a situation in which stronger IPR enforcement unambiguously enhances $M$ 's profits regardless of its type. We have thus far assumed the strength of IPR enforcement to be identical across the two periods. Suppose that we relax this assumption to allow different IPR enforcement strengths in the two periods. More specifically, let $\gamma_{t}$ be the strength of IPR enforcement in period $t=1,2$, with $\gamma_{2} \geq \gamma_{1}$, meaning that any improvement in the first period is also effective in 
the second. Per condition (11), it is easy to verify that $\gamma_{2}$ has no effect on the first-period behavior of $M$ or its copycats, and hence is inconsequential to social welfare or $M$ 's profit in period 1 . Therefore, regardless of the value of $\gamma_{2}$, the effects of $\gamma_{1}$ on first-period social welfare and $M^{h}$ 's profit remain the same as described in Propositions 7 and 8. Furthermore, because $M$ 's type is fully revealed in the second period in a separating equilibrium, we can apply the same logic as in Proposition 1 to conclude that the only effect of an increased $\gamma_{2}$ is an increase in $M$ 's second-period profit.

Proposition 9 In an imitation equilibrium, deferred improvement in IPR enforcement (i.e., increasing $\gamma_{2}$ without changing $\gamma_{1}$ ) strictly improves the profits of both types of multinationals without affecting the two-period total social surplus.

As in Proposition 7, the social surplus result in Proposition 9 ignores the influences of improved profitability on innovation incentives. Should this effect be taken into account, deferred improvement in IPR enforcement can strictly improve social welfare. Together with Propositions 7 and 8, Proposition 9 offers a possible rationale for deferred IPR improvement in developing countries in which reputation concerns inhibit multinational entry. Because stronger IPR enforcement is most effective in the absence of friction, delaying IPR improvement until after multinationals' strategic entry has helped to overcome information asymmetry can bring unequivocal social gains.

\section{Concluding Remarks}

In this paper, we demonstrate that because developing countries suffer from many forms of imperfection, multinationals may withhold entry for reasons other than weak IPR enforcement. Such withholding allows copycats to operate, giving rise to IPR violations in equilibrium, a point that is largely ignored in the literature. We show that imitation in the shadow of IPR enforcement can be an alternative channel for technology transfer and that strengthening such enforcement may not be in the best interests of either the host country or multinationals.

In addition to imperfect IPR protection, the particular form of imperfection that we focus on herein is the information asymmetry between foreign multinationals and local consumers concerning the quality of the former's product. In the introduction, we stress the pertinence of this form of imperfection in developing countries. It also allows us to explain why the Pareto gains achieved under moderately weak enforcement cannot be attained under perfect enforcement through a contractual arrangement. It would be useful to investigate the other forms of imperfection that may prevent foreign multinationals from entering a developing country even under perfect enforcement.

\section{Appendix: Proof of Proposition 2}

We first consider the iso-profit curves. We plot the iso-profit curves of $\Pi^{j}\left(\left\{\kappa_{1}, \sigma_{1}\right\}, \rho_{2}\right)$ while fixing $\kappa_{1}=0$ in Figure 2, where the solid curve corresponds to $M^{l}$ and the dotted curve corresponds to $M^{h}$. When 


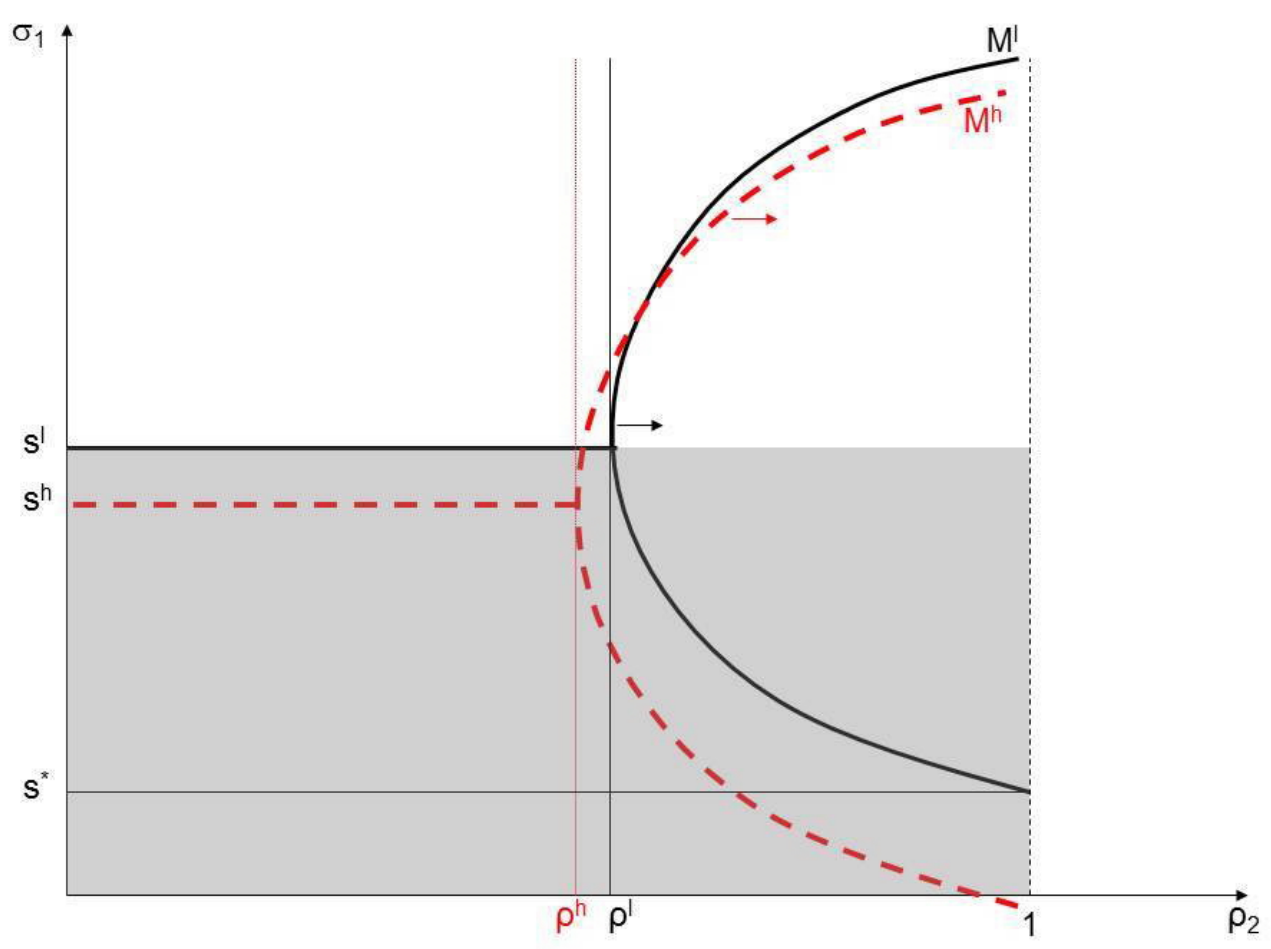

Figure 2: Iso-profit curves when $\kappa_{1}=0$.

$\rho_{2}<\rho^{l}$, the iso-curve of $M^{l}$ is flat because $M^{l}$ chooses licensing in the second period, and consumers' belief thus becomes immaterial. The case is similar for $M^{h}$ when $\rho_{2}<\rho^{h}$. When $\rho_{2}<\rho^{j}$, the iso-profit curve is highest when $\sigma^{j}=s^{j}$ because, with $\rho_{2}$ fixed, the entry profile that maximizes $\Pi^{j}$ is $\left(0, s^{j}\right)$ for $j \in\{h, l\}$. Note that $\rho^{h}>\rho^{l}$ and $s^{h}<s^{l}$.

When $\rho_{2}>\rho^{j}, M^{j}$ adopts direct investment in the second period. Fixing $\rho_{2}$, the entry profile that maximizes $\Pi^{j}$ is $\left(0, s^{j}\right)$ for $j \in\{h, l\}$, and thus all iso-curves of $M^{j}$ are tangent to $\rho_{2}$ at $s^{j}$. As the small arrows indicate, with $\sigma_{1}$ fixed, an iso-curve to the right corresponds to a larger $\Pi^{j}\left(\left\{0, \sigma_{1}\right\}, \rho_{2}\right)$, as a higher $\rho_{2}$ increases $\Pi^{j}$.

The iso-profit curves in Figure 2 satisfy the single-crossing property in the shaded area: $M^{h}$ has an advantage over $M^{l}$ in paying for a better reputation provided that $\sigma_{1}<s^{l}$. The entry profile $\left\{0, s^{*}\right\}$ falls within the shaded area when $\rho_{2}=1$, indicating that it is also feasible for $M^{h}$ to credibly distance itself from $M^{l}$. We now prove the proposition formally in three steps.

Step 1. There exists no pooling equilibrium. Suppose that a pooling equilibrium does exist, where both types choose $\left\{\kappa_{1}, \sigma_{1}\right\}$ in the first period. Then, $\rho_{2}=\rho_{1} . M^{l}$ is willing to choose the equilibrium entry profile only if doing so dominates being itself, that is:

$$
\Pi_{1}^{l}\left(\left\{\kappa_{1}, \sigma_{1}\right\}\right)+\delta \max \left\{y \pi_{k}^{\rho_{1}}-f, y \pi_{s}^{l}\right\} \geq \pi_{s}^{l}+\delta \max \left\{y \pi_{k}^{l}-f, y \pi_{s}^{l}\right\} .
$$


Given the definition of $s^{*}$, the foregoing becomes

$$
\Pi_{1}^{l}\left(\left\{\kappa_{1}, \sigma_{1}\right\}\right)+\delta \max \left\{y \pi_{k}^{\rho_{1}}-f, y \pi_{s}^{l}\right\} \geq \Pi_{1}^{l}\left(\left\{0, s^{*}\right\}\right)+\delta \max \left\{y \pi_{k}^{h}-f, y \pi_{s}^{l}\right\} .
$$

Then, there exists an $s^{\prime}>0$ such that

$$
\Pi_{1}^{l}\left(\left\{0, s^{\prime}\right\}\right)+\delta \max \left\{y \pi_{k}^{h}-f, y \pi_{s}^{l}\right\}=\Pi_{1}^{l}\left(\left\{\kappa_{1}, \sigma_{1}\right\}\right)+\delta \max \left\{y \pi_{k}^{\rho_{1}}-f, y \pi_{s}^{l}\right\} .
$$

The last two observations combined yield

$$
\Pi_{1}^{l}\left(\left\{0, s^{\prime}\right\}\right) \geq \Pi_{1}^{l}\left(\left\{0, s^{*}\right\}\right)
$$

Because $\Pi_{1}^{l}\left(\left\{0, \sigma_{1}\right\}\right)$ is concave (and hence quasi-concave) in $\sigma_{1}$ and maximized at $\sigma_{1}=s^{l}$, $s^{\prime}$ takes two values, one of which falls between $s^{*}$ and $s^{l}$. This $s^{\prime}$ lies in the region in which the iso-profit curves of $M^{h}$ and $M^{l}$ satisfy the single-crossing property, meaning that $M^{h}$ has an advantage over $M^{l}$ in paying for a better reputation. In other words, there exists an $\epsilon>0$ such that $M^{l}$ is not interested in choosing $\left\{0, s^{\prime}-\epsilon\right\}$ regardless of how consumers respond in shaping their subsequent belief:

$$
\Pi_{1}^{l}\left(\left\{0, s^{\prime}-\epsilon\right\}\right)+\delta \max \left\{y \pi_{k}^{h}-f, y \pi_{s}^{l}\right\}<\Pi_{1}^{l}\left(\left\{\kappa_{1}, \sigma_{1}\right\}\right)+\delta \max \left\{y \pi_{k}^{\rho_{1}}-f, y \pi_{s}^{l}\right\} .
$$

$M^{h}$, in contrast, will find such deviation profitable if consumers assign a sufficiently high $\rho_{2}$ after observing it. Hence, the pooling equilibrium fails the intuitive criterion test.

Step 2. In a separating equilibrium, $M^{h}$ chooses no direct investment in the first period (i.e., $\kappa_{1}^{h}=0$ ). Suppose that $M^{h}$ does choose some $\left\{\kappa_{1}^{h}, \sigma_{1}^{h}\right\}$ in such an equilibrium. Without loss of generality, consider $s^{\prime} \in\left(0, s^{l}\right)$ such that ${ }^{10}$

$$
\Pi_{1}^{l}\left(\left\{0, s^{\prime}\right\}\right)=\Pi_{1}^{l}\left(\left\{\kappa_{1}^{h}, \sigma_{1}^{h}\right\}\right) .
$$

Because direct investment in any segment in the first period is unprofitable, it must be true that

$$
s^{\prime}<\sigma_{1}^{h}
$$

Now consider a deviation by $M^{h}$ from $\left\{\kappa_{1}^{h}, \sigma_{1}^{h}\right\}$ to $\left\{0, s^{\prime}\right\}$ in the first period. As $s^{\prime}$ satisfies (17), $M^{l}$ has no incentive to deviate whatever belief consumers would assign following the deviation. However, $M^{h}$ can profit from such deviation provided that consumers respond with a large subsequent belief, $\rho_{2}$. To see this, note that

$$
\Pi_{1}^{l}\left(\left\{0, s^{\prime}\right\}\right)-\Pi_{1}^{h}\left(\left\{0, s^{\prime}\right\}\right)=s^{\prime}\left(c^{h}-c^{l}\right)
$$

whereas

$$
\Pi_{1}^{l}\left(\left\{\kappa_{1}^{h}, \sigma_{1}^{h}\right\}\right)-\Pi_{1}^{h}\left(\left\{\kappa_{1}^{h}, \sigma_{1}^{h}\right\}\right)=\sigma_{1}^{h}\left(c^{h}-c^{l}\right) .
$$

Following (18) and holding $c^{h}>c^{l}$, we have

$$
\Pi_{1}^{l}\left(\left\{0, s^{\prime}\right\}\right)-\Pi_{1}^{h}\left(\left\{0, s^{\prime}\right\}\right)<\Pi_{1}^{l}\left(\left\{\kappa_{1}^{h}, \sigma_{1}^{h}\right\}\right)-\Pi_{1}^{h}\left(\left\{\kappa_{1}^{h}, \sigma_{1}^{h}\right\}\right),
$$

\footnotetext{
${ }^{10}$ If there does not exist an $s^{\prime}>0$ such that equation (17) holds, then it is evident that $M^{h}$ can profitably deviate from $\left\{\kappa_{1}^{h}, \lambda_{1}^{h}\right\}$ to $\left\{0, s^{*}\right\}$ while keeping its distance from $M^{l}$. Given that $s^{\prime}>0$ solves equation (17), as argued in step $1, s^{\prime}$ can take two solutions, with one falling below $s^{l}$.
} 
which in turn implies (given (17))

$$
\Pi_{1}^{h}\left(\left\{0, s^{\prime}\right\}\right)>\Pi_{1}^{h}\left(\left\{\kappa_{1}^{h}, \sigma_{1}^{h}\right\}\right),
$$

meaning that $M^{h}$ can profit from a deviation to $\left\{0, s^{\prime}\right\}$.

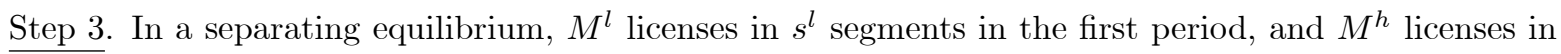
$\min \left\{s^{*}, s^{h}\right\}$ segments. In such an equilibrium, as its type will be fully revealed in the second period, $M^{l}$ chooses $s^{l}$ as in the benchmark case. Given $M^{l}$ 's choice, $M^{h}$ maximizes its own payoff without inducing any mimicking from $M^{l}$ by choosing $\sigma_{1}^{h}=s^{*}$ if $s^{*}<s^{h}$, and $\sigma_{1}^{h}=s^{h}$ if $s^{h} \geq s^{*}$.

Q.E.D.

\section{References}

[1] Aghion, P., Bloom, N., Blundell, R., Griffith, R. and Howitt, P. "Competition and innovation: An inverted-U relationship," Quarterly Journal of Economics 120 (2005), 701-728.

[2] Aghion, P., Harris, C., Howitt, P. and Vickers, J. "Competition, imitation and growth with step-bystep innovation," Review of Economic Studies 68 (2001), 467-492.

[3] Bessen, J. and Maskin, E. "Sequential innovation, patents, and imitation," Rand Journal of Economics 40 (2009), 611-635.

[4] Branstetter, L., Fisman, R. and Foley, C. F. "Do stronger intellectual property rights increase international technology transfer? Empirical evidence from U.S. firm-level panel data," Quarterly Journal of Economics 484 (2006), 321-349.

[5] Branstetter, L., Fisman, R., Foley, C. F. and Saggi, K. "Does intellectual property rights reform spur industrial development?" Journal of International Economics 83 (2011), 27-36.

[6] Branstetter, L. and Saggi, K. "Intellectual property rights, foreign direct investment, and industrial development," Economic Journal 121 (2011), 1161-1191.

[7] Che, J., Qiu, L. D. and Zhou, W. "Entry, reputation, and intellectual property rights enforcement," working paper, 2012.

[8] Cho, I. and Kreps, D. M. "Signaling games and stable equilibria," The Quarterly Journal of Economics 102 (1987), 179-221.

[9] Dinopoulos, E. and Segerstrom, P. "Intellectual property rights, multinational firms and economic growth," Journal of Development Economics 92 (2010), 13-27.

[10] The Economist, "(Still) made in Japan," Apr, 7th, 2004, print edition.

[11] Ethier, W. J. and Markusen, J. R. "Multinational firms, technology diffusion and trade," Journal of International Economics 41 (1996), 1-28.

[12] Glass, A. J. and Saggi, K. "Intellectual property rights and foreign direct investment," Journal of International Economics 56 (2002), 387-410.

[13] Glass, A. J. and Wu, X. "Intellectual property rights and quality improvement," Journal of Development Economics 82 (2007), 393-415. 
[14] Grossman, G. M. and Helpman, E. "Quality ladders and product cycles," The Quarterly Journal of Economics 106 (1991), 557-586.

[15] Gustafsson, P. and Segerstrom, P. S. "North-South trade with multinational firms and increasing product variety," International Economic Review 52 (2011), 1123-1155.

[16] Head, K. and Ries, J. "Heterogeneity and the FDI versus export decision of Japanese manufacturers," Journal of the Japanese and International Economies 17 (2003), 448-467.

[17] Helpman, E. "Innovation, imitation and intellectual property rights," Econometrica 61 (1993), 12471280.

[18] Ivus, O. "Do stronger patent rights raise high-tech exports to the developing world?" Journal of International Economics 81 (2010), 38-47.

[19] Lai, E. L. C. "International intellectual property rights protection and the rate of product innovation," Journal of Development Economics 55 (1998), 133-153.

[20] Maskus, K. E. and Penubarti, M. "How trade-related are intellectual property rights?" Journal of International Economics 39 (1995), 227-248.

[21] McKinsey and Company. "Understanding China's growing love for luxury," McKinsey Consumer and Shopper Insights (2011).

[22] Parello, C. P. "A North-South model of intellectual property rights protection and skill accumulation," Journal of Development Economics 85 (2008), 253-281.

[23] Scherer, F. "Market structure and the employment of scientists and engineers," American Economic Review 57 (1967), 524-531.

[24] Segerstrom, P. S., Anant, T. C. A. and Dinopoulos, E., "A Schumpeterian model of the product life cycle," American Economic Review, 80 (1990), 1077-1091.

[25] Smith, P. J. "How do foreign patent rights affect U.S. exports, affiliate sales, and licenses?" Journal of International Economics 55 (2001), 411-439.

[26] Spence, M. "Job market signaling," The Quarterly Journal of Economics 87 (1973), 355-374.

[27] Yang, G. and Maskus, K. E. "Intellectual property rights, licensing, and innovation in an endogenous product-cycle model," Journal of International Economics 53 (2001), 169-187.

[28] Yang, L. and Maskus, K. E. "Intellectual property rights, technology transfer and exports in developing countries," Journal of Development Economics 90 (2009), 231-236. 